\title{
Smoking, Gender, and Overweight Are Important Influencing Factors on Monocytic HLA-DR before and after Major Cancer Surgery
}

\author{
Gunnar Lachmann, ${ }^{1}$ Clarissa von Haefen, ${ }^{1}$ Johannes Kurth, ${ }^{1}$ Fatima Yuerek, ${ }^{1}$ \\ Klaus-Dieter Wernecke, ${ }^{2}$ and Claudia Spies ${ }^{1}$ \\ ${ }^{1}$ Department of Anesthesiology and Operative Intensive Care Medicine, Charité - Universitätsmedizin Berlin, \\ Campus Charité Mitte and Campus Virchow-Klinikum, Berlin, Germany \\ ${ }^{2}$ Sostana GmbH, Berlin, Germany \\ Correspondence should be addressed to Claudia Spies; claudia.spies@charite.de \\ Gunnar Lachmann and Clarissa von Haefen contributed equally to this work.
}

Received 20 February 2017; Revised 24 May 2017; Accepted 9 July 2017; Published 8 August 2017

Academic Editor: Giuseppe Valacchi

Copyright (C) 2017 Gunnar Lachmann et al. This is an open access article distributed under the Creative Commons Attribution License, which permits unrestricted use, distribution, and reproduction in any medium, provided the original work is properly cited.

\begin{abstract}
Background. Monocytic human leukocyte antigen D related (mHLA-DR) is essential for antigen-presentation. Downregulation of mHLA-DR emerged as a general biomarker of impaired immunity seen in patients with sepsis and pneumonia and after major surgery. Influencing factors of mHLA-DR such as age, overweight, diabetes, smoking, and gender remain unclear. Methods. We analyzed 20 patients after esophageal or pancreatic resection of a prospective, randomized, placebo-controlled, double-blind trial (placebo group). mHLA-DR was determined from day of surgery (od) until postoperative day (pod) 5. Statistical analyses were performed using multivariate generalized estimating equation analyses (GEE), nonparametric multivariate analysis of longitudinal data, and univariate post hoc nonparametric Mann-Whitney tests. Results. In GEE, smoking and gender were confirmed as significant influencing factors over time. Univariate analyses of mHLA-DR between smokers and nonsmokers showed lower preoperative levels $(p=0.010)$ and a trend towards lower levels on pod5 $(p=0.056)$ in smokers. Lower mHLA-DR was seen in men on pod3 $(p=0.038)$ and on pod5 $(p=0.026)$. Overweight patients (BMI $\left.>25 \mathrm{~kg} / \mathrm{m}^{2}\right)$ had lower levels of mHLA-DR on pod3 $(p=0.039)$ and pod4 $(p=0.047)$. Conclusion. Smoking is an important influencing factor on pre- and postoperative immune function while postoperative immune function was influenced by gender and overweight. Clinical trial registered with ISRCTN27114642.
\end{abstract}

\section{Background}

Antigen-presenting cells, that is, macrophages, dendritic cells, and activated natural killer cells, express human leukocyte antigen D related (HLA-DR) on their surface which is crucial for immunologic competence [1,2]. Immunogenic peptides processed from ingested pathogens, for example, bacterial proteins, are presented to $\mathrm{T}$ cells by HLA-DR. Specific $\mathrm{T}$ cell antigen receptors recognize the HLA-DRantigen complex and subsequently activate the $\mathrm{T}$ cells [3]. Thus, the expression of HLA-DR reflects the functional state of antigen-presenting cells.
Downregulation of HLA-DR expression on monocytes (mHLA-DR) emerged as a general biomarker of impaired immunity up to immune suppression which can predict outcome $[1,4,5]$. In the state of reduced mHLA-DR expression, the function of monocytes and $\mathrm{T}$ cell activation is severely restricted [6] which results in up to five times higher risk for infections and septic complications [7-9]. A reduced mHLA-DR expression is associated with sepsis, pneumonia, and surgical site infections [9-11] and furthermore seen in patients after thoracic $[12,13]$ and major visceral surgery $[1,3,14]$, in trauma patients $[15,16]$ and patients with burn injury [17]. 
We and others used mHLA-DR expression to stratify immune compromised patients after surgery $[18,19]$ and during severe sepsis [20]. In both settings, mHLA-DR could be increased through administration of GM-CSF restoring immune function and improving outcome. However, reasons for a decreased mHLA-DR expression frequently seen after major surgery and during sepsis are not clearly understood. Surgical stress and tissue damage resulting in an inflammatory state are proposed to downregulate mHLA-DR through cortisol and interleukin- (IL-) 10 [21, 22].

Various conditions can alter immune function generally and particularly after surgery. Ageing [23, 24], obesity [25], diabetes [26, 27], gender [1], and smoking [28, 29] have an influence on the immune function, immune cells, and cytokines. Smoking is suggested to trigger the development of rheumatoid arthritis or multiple sclerosis due to interactions between subtypes of HLA-DR alleles [30-32]. Furthermore, smokers showed a decreased $\mathrm{T}$ cell function and a higher rate of HLA-DR positive T cells, that is, a higher activation [33]. Ono et al. found lower levels of mHLA-DR in men compared to women on the first day after gastrectomy [1]. However, the influence of age, BMI, diabetes, and smoking on pre- and postoperative mHLA-DR and immune function is unclear. Thus, we analyzed mHLA-DR after major cancer surgery regarding influencing factors such as age, overweight, diabetes, smoking, gender, and surgical time.

\section{Patients and Methods}

2.1. Study Participants and Design. This retrospective subgroup analysis refers to a previously published study of our research group [18] which studied mHLA-DR in 20 out of 61 immune suppressed patients (mHLA-DR levels below 10,000 $\mathrm{mAb}$ per cell on pod1) from od until pod5 after elective esophageal or pancreatic resections since these subgroup patients were not treated with study medication (Figure 1). All patients received guideline-based anesthesiological and surgical treatment according to our standard operating procedures [34].

2.2. Measurement of mHLA-DR, Leukocytes, and C-Reactive Protein. Blood samples were taken from od until pod5 and intraoperative parameters (surgical time, blood glucose and lactate levels, and blood pressure) were documented. mHLA$\mathrm{DR}$, leukocytes, and C-reactive protein (CRP) were measured in all patients from od until pod5 in cooperation with the Institute of Medical Immunology and Berlin-Brandenburg Center for Regenerative Therapies (BCRT), Charité - Universitätsmedizin Berlin, Berlin, Germany. mHLA-DR was measured using a highly standardized quantitative assay as described earlier [8]. Plasma levels of CRP were measured by an immunoturbidimetric assay (Roche Diagnostics, Mannheim, Germany) whereas white blood cell analyses were performed on a standard hematology analyzer (Sysmex $\mathrm{GmbH}$, Norderstedt, Germany).

2.3. Clinical Outcome Parameters. During the follow-up period until pod9, we determined infections according to

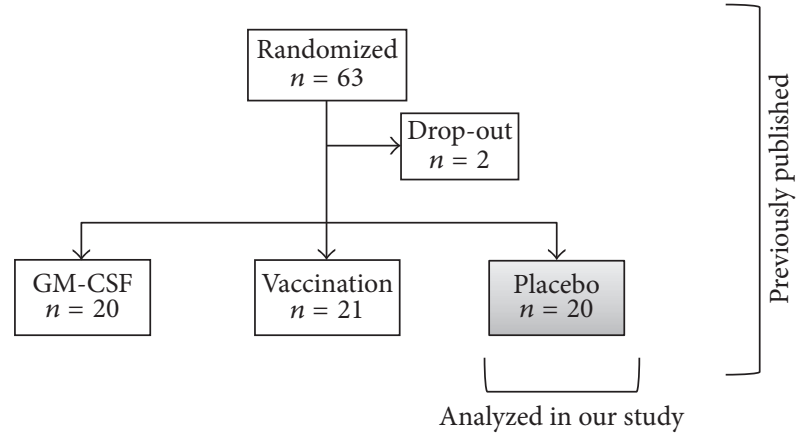

FIgURE 1: Consort diagram.

the standards of the CDC and ATS criteria for pneumonia $[35,36]$, incidence of delirium using Delirium Detection Score (DDS, [37]) with a DDS $>3$, and hospital and ICU stay.

2.4. Statistical Analysis. Data were expressed according to their scaling as arithmetic mean \pm standard deviation (SD), median [25\%, 75\% quartiles], or frequencies [\%], respectively. After exploratory data analysis, all tests were accomplished by means of nonparametric exact statistical tests. Basic patient characteristics were evaluated for group differences using the Mann-Whitney tests for continuous variables and the Fisher exact test for categorical variables. To detect influences on mHLA-DR, we used multivariate generalized estimating equation (GEE) over the six time points with mHLA-DR as dependable variable and gender, smoking, diabetes, BMI, age, and surgical time as independent variables. Significant variables in GEE were taken as risk factors for mHLA-DR in a multivariate nonparametric analysis of longitudinal data in a two-factorial design and judged for corresponding impact. This analysis tests for three hypotheses, namely, differences in risk factors, systematic changes over time, and interactions between differences and time. After such global testing, univariate tests were further carried out as post hoc analyses to detect specific differences with respect to those groups for fixed times (exact Mann-Whitney tests). A two-tailed $p$ value $<0.05$ was considered statistically significant. All tests were conducted in the area of exploratory data analysis. Therefore, no adjustments for multiple testing have been made. The calculations were performed with IBM( $\odot$ SPSS( $\odot$ Statistics, Version 23 and SAS, Version 9.1, Copyright@ by SAS Institute, Inc., Cary, NC, USA.

\section{Results}

3.1. Study Population. All analyses were performed in 20 patients of the placebo group from od until pod5. mHLA-DR, leukocytes, and CRP were measured in all patients.

3.2. Multivariate Analyses (GEE) of Influencing Factors on $m H L A-D R$. Multivariate GEE was conducted in 20 patients from od until pod5 using mHLA-DR as responder and diabetes, BMI (dichotomized as overweight with $\leq 25$ versus $>25 \mathrm{~kg} / \mathrm{m}^{2}$ ), smoking, gender, surgical time, and age as influencing factors. Smoking $(p=0.002)$ and gender $(p=0.026)$ 


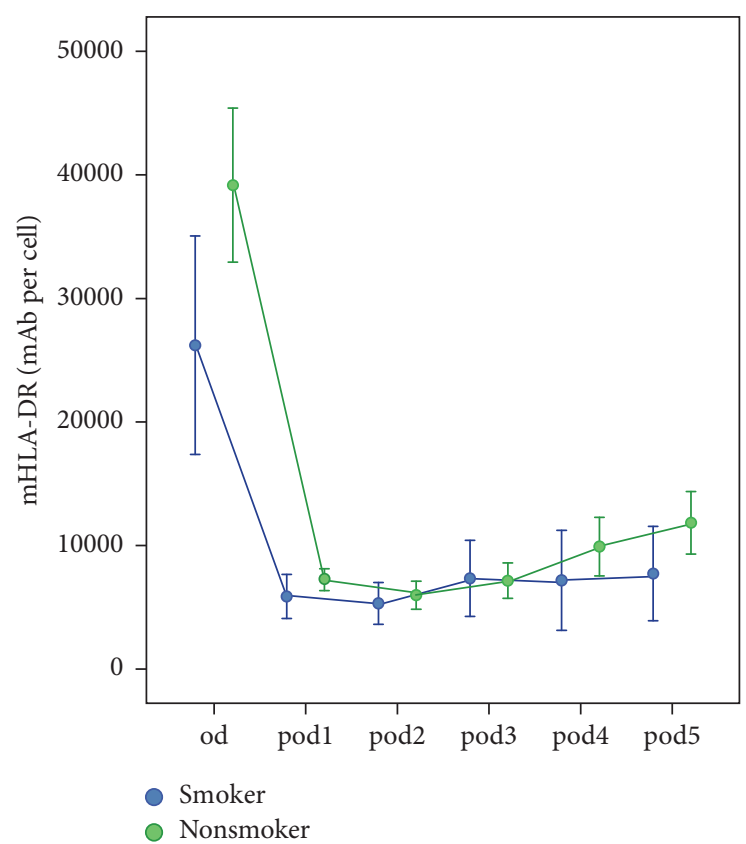

FIGURE 2: Monocytic HLA-DR (mHLA-DR) immediately before surgery (od) until day 5 after surgery (pod5) between smokers and nonsmokers (error bars with $95 \%$ confidence interval). mHLA-DR was lower in smokers on $o d(p=0.010), \operatorname{pod} 4(p=0.098)$, and pod5 $(p=0.056)$.

were confirmed as influencing factors over time. Therefore, smoking and gender were taken as risk factors in multivariate longitudinal analyses together with overweight for clinical reasons.

3.3. Influence of Smoking on mHLA-DR. 8 out of the 20 patients were active smokers. Differences in basic patient characteristics did not differ between smokers and nonsmokers. The longitudinal analysis revealed no significant risk factor differences $(p=0.142)$ but resulted in significant changes over time $(p<0.001)$ and interactions $(p=0.038)$, which showed increasing differences over time. In univariate analyses, preoperative mHLA-DR was significantly lower in smokers $(p=0.010$; Figure 2$)$ whereas a trend towards lower levels was seen on pod4 $(p=0.098)$ and pod5 $(p=0.056)$ in smokers. Leukocytes and CRP did not differ from od until pod5 except for a trend towards higher CRP on pod1 ( $p=$ $0.053)$ in smokers. Furthermore, smokers revealed a longer ICU stay $(p=0.047)$. Differences are shown in Table 1 .

3.4. Influence of Overweight on $m H L A-D R$. Groups were divided into normal weight $\left(\mathrm{BMI} \leq 25 \mathrm{~kg} / \mathrm{m}^{2}\right)$ and overweight $\left(\mathrm{BMI}>25 \mathrm{~kg} / \mathrm{m}^{2}\right) .12$ out of 20 patients were overweight. No differences in basic patient characteristics occurred. The longitudinal analysis revealed no significant risk factor differences $(p=0.079)$ but resulted in significant changes over time $(p<0.001)$ and interactions $(p=0.011)$, which showed increasing differences over time. In univariate analyses, mHLA-DR was lower in overweight patients on $\operatorname{pod} 3(p=0.039)$ and on $\operatorname{pod} 4(p=0.047$; Figure 3$)$.
TABLE 1: Basic patient characteristics and outcome parameters between smokers and nonsmokers from od until pod5.

\begin{tabular}{lccc}
\hline & Smokers $(n=8)$ & $\begin{array}{c}\text { Nonsmokers } \\
(n=12)\end{array}$ & $p$ value \\
\hline Age [years] & $64(56-69)$ & $66(55-75)$ & 0.521 \\
BMI [kg/m ${ }^{2}$ ] & $25.9(20.8-28.6)$ & $25.4(24.3-27.8)$ & 0.792 \\
Gender [m/f] & $5 / 3$ & $6 / 6$ & 0.670 \\
ASA score II/III [n] & $3 / 5$ & $9 / 3$ & 0.167 \\
$\begin{array}{l}\text { Diabetes in history } \\
\text { [no/yes] }\end{array}$ & $7 / 1$ & $9 / 3$ & 0.619 \\
Surgical time [min] & $323(305-405)$ & $296(231-367)$ & 0.305 \\
Periop. blood glucose & $124(120-138)$ & $131(119-143)$ & 0.624 \\
[mg/dL] & & & \\
Periop. blood lactate & $1.2(0.9-1.3)$ & $0.9(0.8-1.1)$ & 0.057 \\
[mmol/L] (max.) & & & \\
Periop. systolic blood & $122(109-137)$ & $114(112-116)$ & 0.270 \\
pressure [mmHg] & & $12.2(8.3-16.9)$ & 0.053 \\
CRP on pod1 [mg/dL] & $8.3(7.6-9.3)$ & $3.5(1.2-4.5)$ & $\mathbf{0 . 0 4 7}$ \\
ICU stay [d] & $5.4(3.0-8.9)$ & $15.4(12.3-18.8)$ & 0.384 \\
Hospital stay [d] & $19.0(12.3-36.0)$ & $6 / 6$ & 0.670 \\
Delirium [no/yes] & $3 / 5$ & $7 / 5$ & 0.197 \\
\hline Infection [no/yes] & $2 / 6$ & &
\end{tabular}

Leukocytes, CRP, and outcome parameters did not differ between normal weight and overweight patients. Differences are shown in Table 2.

3.5. Influence of Gender on $m H L A-D R .11$ out of 20 patients were male. Differences in basic patient characteristics occurred in BMI. The longitudinal analysis revealed no significant risk factor differences $(p=0.067)$ but resulted in significant changes over time $(p<0.001)$. In univariate analyses, mHLA-DR was lower in men on pod3 $(p=0.038)$ and on pod5 ( $p=0.026$; Figure 4$)$. Leukocytes and outcome parameters did not differ between the groups. CRP was higher in men on pod1 $(p=0.019)$. Differences are shown in Table 3.

\section{Discussion}

The major finding of this subanalysis is that pre- and postoperative mHLA-DR were influenced by smoking, gender, and overweight. Smokers revealed an attenuated pre- and postoperative immune function, whereas recovery of mHLADR was better in normal weight patients, women, and nonsmokers. This is an important finding, particularly with regard to the impact of smoking on pre- and postoperative function on the immune system. To the best of our knowledge, no other study has investigated influencing factors on postoperative mHLA-DR up to date.

HLA-DR is a key molecule on antigen-presenting cells and a marker of impaired immunity and immune suppression, for example, during sepsis and after surgery $[1,4,5]$. We found lower values of mHLA-DR preoperatively in smokers as well as higher levels of CRP and a delayed recovery 
TABLE 2: Basic patient characteristics and outcome parameters between normal (BMI $\leq 25 \mathrm{~kg} / \mathrm{m}^{2}$ ) and overweight patients (BMI $>25 \mathrm{~kg} / \mathrm{m}^{2}$ ).

\begin{tabular}{lccc}
\hline & $\begin{array}{c}\text { Normal weight } \\
(n=8)\end{array}$ & $\begin{array}{c}\text { Overweight } \\
(n=12)\end{array}$ & $p$ value \\
\hline Age [years] & $66(61-72)$ & $61(54-74)$ & 0.384 \\
Gender [m/f] & $3 / 5$ & $8 / 4$ & 0.362 \\
ASA score II/III [ $n$ ] & $5 / 3$ & $7 / 5$ & 1.000 \\
Smokers/nonsmokers & $3 / 5$ & $5 / 7$ & 1.000 \\
[n] & & & \\
$\begin{array}{l}\text { Diabetes in history } \\
\text { [no/yes] }\end{array}$ & $6 / 2$ & $10 / 2$ & 1.000 \\
$\begin{array}{l}\text { Surgical time [min] } \\
\text { Periop. blood glucose }\end{array}$ & $294(231-388)$ & $332(287-383)$ & 0.343 \\
[mg/dL] & $128(119-145)$ & $127(120-138)$ & 0.678 \\
Periop. blood lactate & $1.0(0.8-1.2)$ & $1.1(0.8-1.2)$ & 0.792 \\
[mmol/L] (max.) & & $115(113-119)$ & 1.000 \\
Periop. syst. blood & $115(111-123)$ & & \\
pressure [mmHg] & $4.0(0.9-5.6)$ & $3.9(2.9-4.9)$ & 0.678 \\
ICU stay [d] & $13.5(11.1-29.4)$ & $(13.9-22.2)$ & 0.427 \\
Hospital stay [d] & $4 / 4$ & $5 / 7$ & 1.000 \\
Delirium [no/yes] & $5 / 3$ & $4 / 8$ & 0.362 \\
\hline Infection [no/yes] & & &
\end{tabular}

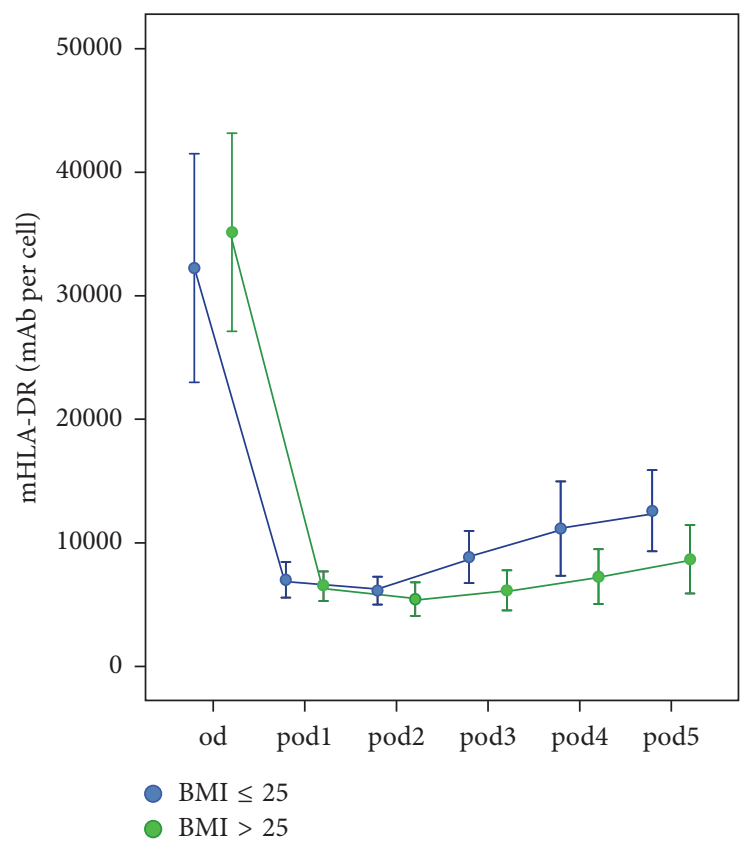

FIGURE 3: Monocytic HLA-DR (mHLA-DR) immediately before surgery $(o d)$ until day 5 after surgery (pod5) between normal weight and overweight patients (error bars with 95\% confidence interval). Lower levels of mHLA-DR were seen on pod3 $(p=0.039)$ and on pod4 ( $p=0.047)$ in overweight patients.

of mHLA-DR after surgery. Smoking might therefore have direct influences on pre- and postoperative immune function, a generally lower immunity, and delayed recovery of immune suppression after surgery. Most likely, these alterations
TABLE 3: Basic patient characteristics and outcome parameters between men and women.

\begin{tabular}{lccc}
\hline & Men $(n=11)$ & $\begin{array}{c}\text { Women } \\
(n=9)\end{array}$ & $p$ value \\
\hline Age [years] & $60(54-67)$ & $69(60-76)$ & 0.067 \\
BMI [kg/m²] & 27.2 & 24.3 & $\mathbf{0 . 0 4 6}$ \\
Smokers/nonsmokers & $(24.5-28.9)$ & $(21.0-25.7)$ & \\
$\begin{array}{l}\text { n] } \\
\text { ASA score II/III [ } n \text { ] }\end{array}$ & $5 / 6$ & $3 / 6$ & 0.670 \\
$\begin{array}{l}\text { Diabetes in history } \\
\text { [no/yes] }\end{array}$ & $9 / 2$ & $3 / 6$ & 0.065 \\
$\begin{array}{l}\text { Surgical time [min] } \\
\text { Periop. blood glucose }\end{array}$ & $315(281-385)$ & $315(235-394)$ & 0.766 \\
[mg/dL] & $131(123-141)$ & $123(110-138)$ & 0.331 \\
$\begin{array}{l}\text { Periop. blood lactate } \\
\text { [mmol/L] (max.) }\end{array}$ & $1.7(1.1-2.3)$ & $1.3(1.1-1.7)$ & 0.503 \\
$\begin{array}{l}\text { Periop. systolic blood } \\
\text { pressure [mmHg] }\end{array}$ & $116(113-123)$ & $113(111-118)$ & 0.331 \\
CRP on pod1 [mg/dL] & 10.6 & $7.7(6.4-8.7)$ & $\mathbf{0 . 0 1 9}$ \\
ICU stay [d] & $(8.8-14.9)$ & $3.8(0.9-5.3)$ & 0.456 \\
Hospital stay [d] & $4.0(2.9-4.9)$ & 15.9 & 1.000 \\
$\begin{array}{l}\text { Delirium [no/yes] } \\
\text { Infection [no/yes] }\end{array}$ & $(12.0-23.0)$ & $(12.4-25.8)$ & 0.653 \\
\hline & $4 / 7$ & $5 / 4$ & 0.653 \\
\hline
\end{tabular}

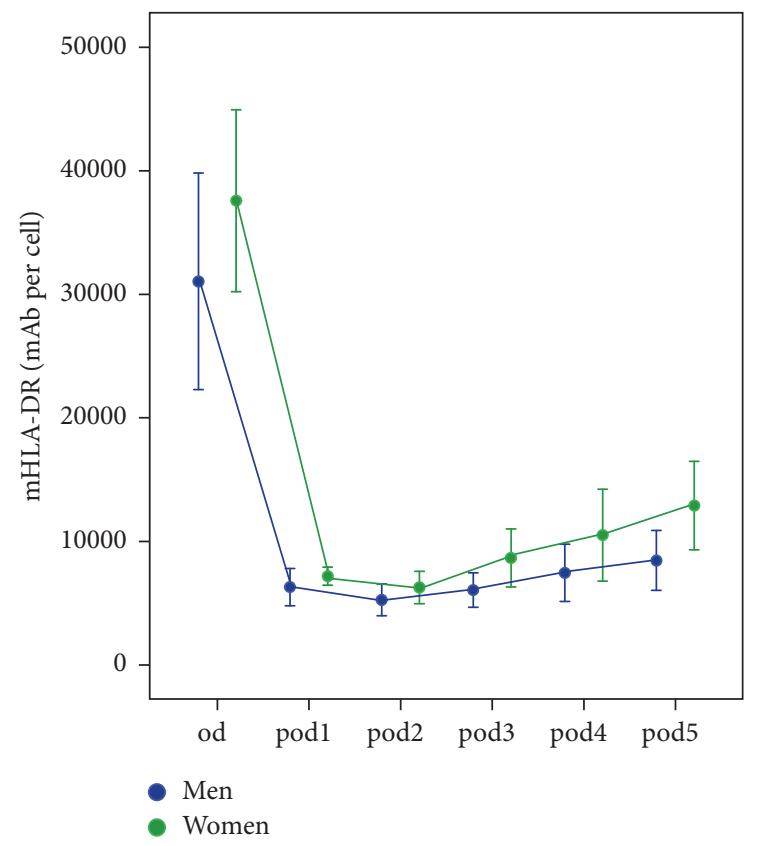

FIGURE 4: Monocytic HLA-DR (mHLA-DR) immediately before surgery (od) until day 5 after surgery (pod5) between men and women (error bars with $95 \%$ confidence interval). mHLA-DR was lower in men on pod3 $(p=0.038)$ and on pod5 $(p=0.026)$.

resulted in outcome differences seen in a prolonged ICU stay in smokers. Shiels et al. found a decrease of inflammatory markers and an increase in CRP in long-term smokers [29] whereas Hiemstra et al. could show that inflammation is 
increased and host defence against infections is decreased by cigarette smoke [38]. In accordance with Hiemstra et al., we observed an increased inflammation by CRP and a decreased host immunity by mHLA-DR. Dogan et al. conclude that regular smoking correlates with alterations in peripheral mononuclear cells interfering inflammatory and immune function pathways [28]. In previous studies, smoking showed significant interactions with subtypes of HLA-DR alleles and therefore increased the risk of developing rheumatoid arthritis or multiple sclerosis [30-32]. Unfortunately, our study was not designed to analyze these interactions but most likely smoking influences not only subtypes of HLADR alleles, but also mHLA-DR expression. Our analyses show that smoking is not only related to postoperative complications such as cardiovascular [39], respiratory [40], and wound complications [41], but also related to preoperative immunological complications that might influence or induce postoperative complications. We hypothesize that regular smoking has long-term effects on immunity through directly affecting mHLA-DR. After surgery, mHLA-DR remains impaired resulting in a delayed recovery which increases the risk of postoperative complications [9]. Further studies are warranted to evaluate potential pathological mechanisms.

Additionally, we found a delayed recovery of mHLADR in overweight patients after surgery. Likewise diabetes, obesity generally constitutes a chronic inflammatory state, particularly elevated leukocyte counts, activity of granulocyte phagocytosis and oxidative burst, and increased levels of TNF- $\alpha$ and IL-6 $[23,25,26]$. Obesity is also an important risk factor for increased mortality up to $20 \%$ and a shortened life expectancy up to 2 to 4 years $[42,43]$. In various surgical procedures, overweight or obesity can lead to an increased risk of postoperative infections [44-47]. We have not seen increased CRP or leukocytes in overweight patients but an increased risk for postoperative complications by a delayed recovery of $\mathrm{mHLA-DR}$ [9]. In summary, overweight patients had a postoperatively impaired immunity and thus most likely an increased risk for postoperative complications.

In GEE, we found differences in postoperative mHLADR between men and women over time and lower postoperative levels in men in univariate analyses. Gender generally constitutes an unmodifiable risk factor for postoperative complications [48]. Ono et al. investigated postoperative mHLA-DR and also found lower levels in men on day one after gastrectomy but did not study further courses as we did [1]. In clinical studies, male patients showed a 2 times higher risk for postoperative infections and a 1.6 times higher rate of pneumonia $[49,50]$ whereas women with nosocomial infections are at higher lethality up to 2 times [51-53]. Additionally, women showed better outcomes after sepsis [54, 55].

Age and surgical time are also described as influencing factors on postoperative immune function. Ono et al. found an increased activation of monocytes and raised levels of proinflammatory cytokines in elderly patients after surgery [24]. Sutherland et al. demonstrated a reduced immune response in elderly patients after surgery [56]. Surgical time contributes also as a risk factor for postoperative infections [57]. However, we did not see any influence of surgical time or age on mHLA-DR.
Limitations of these analyses are first a small sample size of 20 patients and therefore, no immune cells and cytokines except for leukocytes and CRP were analyzed. Though significant differences occurred, a higher sample size could have shown more reliable results. Furthermore, we analyzed mHLA-DR of postoperative immune suppressed patients with a threshold level for mHLA-DR of $\leq 10,000 \mathrm{mAb} / \mathrm{cell}$. Hence, the influence on mHLA-DR in less suppressed or unsuppressed patients remains unclear.

\section{Conclusion}

Smokers revealed a preoperative impaired mHLA-DR expression and a delayed recovery after surgery. Overweight patients as well as men showed a delayed recovery of mHLA-DR after surgery. This is an important finding, particularly with regard to the impact of smoking on pre- and postoperative function on the immune system. Smoking and overweight are therefore risk factors for an impaired immunity after surgery and an increased risk for postoperative complications.

\section{Disclosure}

The study was performed at the Department of Anesthesiology and Operative Intensive Care Medicine, Campus Charité Mitte and Campus Virchow-Klinikum, Charité Universitätsmedizin Berlin, Germany. The funders Deutsche Forschungsgemeinschaft (DFG SP432-1, http://www.dfg.de/) and Charité - Universitätsmedizin Berlin (http://www.charite .de) had no role in and no influence on study design, data collection, data analysis, decision to publish, or preparation of the manuscript. Preliminary data of this manuscript were presented at DAC 2017, Nuremberg, Germany, as an e-poster.

\section{Conflicts of Interest}

Statistical analysis has been supervised by Professor KlausDieter Wernecke, Ph.D., former head of the Institute of Medical Biometry at Charité - Universitätsmedizin Berlin and owner of Sostana GmbH.

\section{Authors' Contributions}

Claudia Spies and Klaus-Dieter Wernecke conceived and designed the experiments. Gunnar Lachmann, Clarissa von Haefen, Johannes Kurth, and Fatima Yuerek performed the experiments. Gunnar Lachmann, Clarissa von Haefen, and Klaus-Dieter Wernecke analyzed the data. Clarissa von Haefen and Klaus-Dieter Wernecke contributed materials/analysis tools. Gunnar Lachmann, Clarissa von Haefen, Johannes Kurth, Fatima Yuerek, Claudia Spies, and KlausDieter Wernecke wrote the paper.

\section{Acknowledgments}

The authors are very grateful to Kathrin Scholtz for monitoring this study and to Anja-Vanessa Philippeit, Dominik 
Stöber, Julia Schäfer, Carolyn Geipel, and Kay Dittrich for data acquisition and help with the data base. They thank Victoria Windmann and Mirion Glas for their help with the manuscript.

\section{References}

[1] S. Ono, H. Tsujimoto, S.-I. Hiraki, R. Takahata, M. Kinoshita, and H. Mochizuki, "Sex differences in cytokine production and surface antigen expression of peripheral blood mononuclear cells after surgery," American Journal of Surgery, vol. 190, no. 3, pp. 439-444, 2005.

[2] M. J. O’Dwyer, H. C. Owen, and H. D. T. Torrance, "The perioperative immune response," Current Opinion in Critical Care, vol. 21, no. 4, pp. 336-342, 2015.

[3] D. Mokart, J. Textoris, L. Chow-Chine et al., "HLA-DR and B7-2 (CD86) monocyte expressions after major cancer surgery: Profile in sepsis," Minerva Anestesiologica, vol. 77, no. 5, pp. 522527, 2011.

[4] S. Cajander, A. Bäckman, E. Tina, K. Strålin, B. Söderquist, and J. Källman, "Preliminary results in quantitation of HLADRA by real-time PCR: a promising approach to identify immunosuppression in sepsis," Critical Care, vol. 17, no. 5, article no. R223, 2013.

[5] T. Fumeaux and J. Pugin, "Is the measurement of monocytes HLA-DR expression useful in patients with sepsis?" Intensive Care Medicine, vol. 32, no. 8, pp. 1106-1108, 2006.

[6] K. Wolk, W.-D. Döcke, V. Von Baehr, H.-D. Volk, and R. Sabat, "Comparison of monocyte functions after LPS- or IL-10induced reorientation: importance in clinical immunoparalysis," Pathobiology, vol. 67, no. 5-6, pp. 253-256, 1999.

[7] C. D. Spies, V. Von Dossow, V. Eggers et al., "Altered cellmediated immunity and increased postoperative infection rate in long-term alcoholic patients," Anesthesiology, vol. 100, no. 5, pp. 1088-1100, 2004.

[8] W.-D. Döcke, C. Höflich, K. A. Davis et al., "Monitoring temporary immunodepression by flow cytometric measurement of monocytic HLA-DR expression: A multicenter standardized study," Clinical Chemistry, vol. 51, no. 12, pp. 2341-2347, 2005.

[9] A. Cheron, B. Floccard, B. Allaouchiche et al., "Lack of recovery in monocyte human leukocyte antigen-DR expression is independently associated with the development of sepsis after major trauma," Critical Care, vol. 14, no. 6, article R208, 2010.

[10] C. Landelle, A. Lepape, N. Voirin et al., "Low monocyte human leukocyte antigen-DR is independently associated with nosocomial infections after septic shock," Intensive Care Medicine, vol. 36, no. 11, pp. 1859-1866, 2010.

[11] J.-F. Wu, J. Ma, J. Chen et al., "Changes of monocyte human leukocyte antigen-DR expression as a reliable predictor of mortality in severe sepsis," Critical Care, vol. 15, no. 5, article R220, 2011.

[12] W. Oczenski, H. Krenn, R. Jilch et al., "HLA-DR as a marker for increased risk for systemic inflammation and septic complications after cardiac surgery," Intensive Care Medicine, vol. 29, no. 8, pp. 1253-1257, 2003.

[13] T. Volk, U. R. Döpfmer, M. Schmutzler et al., "Stress induced IL10 does not seem to be essential for early monocyte deactivation following cardiac surgery," Cytokine, vol. 24, no. 6, pp. 237-243, 2003.

[14] A. A. F. A. Veenhof, C. Sietses, B. M. E. Von Blomberg et al., "The surgical stress response and postoperative immune function after laparoscopic or conventional total mesorectal excision in rectal cancer: a randomized trial," International Journal of Colorectal Disease, vol. 26, no. 1, pp. 53-59, 2011.

[15] M. Ploder, L. Pelinka, C. Schmuckenschlager et al., "Lipopolysaccharide-induced tumor necrosis factor $\alpha$ production and not monocyte human leukocyte antigenDR expression is correlated with survival in septic trauma patients," Shock, vol. 25, no. 2, pp. 129-134, 2006.

[16] S. Flohé, S. Lendemans, F.-U. Schade, E. Kreuzfelder, and C. Waydhas, "Influence of surgical intervention in the immune response of severely injured patients," Intensive Care Medicine, vol. 30, no. 1, pp. 96-102, 2004.

[17] C. Sachse, M. Prigge, G. Cramer, N. Pallua, and E. Henkel, "Association between reduced human leukocyte antigen (HLA)-DR expression on blood monocytes and increased plasma level of interleukin-10 in patients with severe burns," Clinical Chemistry and Laboratory Medicine, vol. 37, no. 3, pp. 193-198, 1999.

[18] C. Spies, A. Luetz, G. Lachmann et al., "Influence of granulocyte-macrophage colony-stimulating factor or influenza vaccination on HLA-DR, infection and delirium days in immunosuppressed surgical patients: double blind, randomised controlled trial," PLoS ONE, vol. 10, no. 12, Article ID 0144003, 2015.

[19] G. Lachmann, J. Kurth, C. von Haefen, F. Yuerek, K. Wernecke, and C. Spies, "In vivo application of granulocyte-macrophage colony-stimulating factor enhances postoperative qualitative monocytic function," International Journal of Medical Sciences, vol. 14, no. 4, pp. 367-375, 2017.

[20] C. Meisel, J. C. Schefold, R. Pschowski et al., "Granulocytemacrophage colony-stimulating factor to reverse sepsisassociated immunosuppression: a double-blind, randomized, placebo-controlled multicenter trial," American Journal of Respiratory and Critical Care Medicine, vol. 180, no. 7, pp. 640-648, 2009.

[21] Y. L. Tulzo, C. Pangault, L. Amiot et al., "Monocyte human leukocyte antigen-DR transcriptional downregulation by cortisol during septic shock," American Journal of Respiratory and Critical Care Medicine, vol. 169, no. 10, pp. 1144-1151, 2004.

[22] T. Fumeaux and J. Pugin, "Role of interleukin-10 in the intracellular sequestration of human leukocyte antigen-DR in monocytes during septic shock," American Journal of Respiratory and Critical Care Medicine, vol. 166, no. 11, pp. 1475-1482, 2002.

[23] R. F. Grimble, "Inflammatory response in the elderly," Current Opinion in Clinical Nutrition and Metabolic Care, vol. 6, no. 1, pp. 21-29, 2003.

[24] S. Ono, S. Aosasa, H. Tsujimoto, C. Ueno, and H. Mochizuki, "Increased monocyte activation in elderly patients after surgical stress," European Surgical Research, vol. 33, no. 1, pp. 33-38, 2001.

[25] J. R. Brestoff and D. Artis, "Immune regulation of metabolic homeostasis in health and disease," Cell, vol. 161, no. 1, pp. 146160, 2015.

[26] P. Dandona, A. Aljada, and A. Bandyopadhyay, "Inflammation: the link between insulin resistance, obesity and diabetes," Trends in Immunology, vol. 25, no. 1, pp. 4-7, 2004.

[27] V. Grossmannm, V. H. Schmitt, T. Zeller et al., "Profile of the immune and inflammatory response in individuals with prediabetes and type 2 diabetes," Diabetes Care, vol. 38, no. 7, pp. 1356-1364, 2015.

[28] M. V. Dogan, B. Shields, C. Cutrona et al., "The effect of smoking on DNA methylation of peripheral blood mononuclear cells 
from African American women," BMC Genomics, vol. 15, no. 1, article 151, 2014.

[29] M. S. Shiels, H. A. Katki, N. D. Freedman et al., "Cigarette smoking and variations in systemic immune and inflammation markers," Journal of the National Cancer Institute, vol. 106, no. 11, 2014.

[30] C. L. Too, A. Yahya, S. Murad et al., "Smoking interacts with HLA-DRB1 shared epitope in the development of anticitrullinated protein antibody-positive rheumatoid arthritis: results from the Malaysian Epidemiological Investigation of Rheumatoid Arthritis (MyEIRA)," Arthritis Research and Therapy, vol. 14, no. 2, article no. R89, 2012.

[31] K. Kim, X. Jiang, J. Cui et al., "Interactions between amino acid-defined major histocompatibility complex class II variants and smoking in seropositive rheumatoid arthritis," Arthritis \& Rheumatology, vol. 67, no. 10, pp. 2611-2623, 2015.

[32] A. K. Hedström, I. L. Bomfim, L. F. Barcellos et al., "Interaction between passive smoking and two HLA genes with regard to multiple sclerosis risk," International Journal of Epidemiology, vol. 43, no. 6, Article ID dyu195, pp. 1791-1798, 2014.

[33] R. Valiathan, M. J. Miguez, B. Patel, K. L. Arheart, and D. Asthana, "Tobacco smoking increases immune activation and impairs T-cell function in HIV infected patients on antiretrovirals: a cross-sectional pilot study," PLoS ONE, vol. 9, no. 5, Article ID e97698, 2014.

[34] C. Spies, W. Kox, M. Kastrup, and C. Melzer-Gartzke, OPs in Intensivmedizin und Notfallmedizin: Alle relevanten Standards und Techniken für die Klinik, Georg Thieme Verlag, Stuttgart, Germany, 2013.

[35] T. C. Horan, R. P. Gaynes, W. J. Martone, W. R. Jarvis, and T. Grace Emori, "CDC definitions of nosocomial surgical site infections, 1992: a modification of CDC definitions of surgical wound infections," American Journal of Infection Control, vol. 20, no. 5, pp. 271-274, 1992.

[36] American Thoracic Society, "Infectious diseases society of a. guidelines for the management of adults with hospital-acquired, ventilator-associated, and healthcare-associated pneumonia," American Journal of Respiratory and Critical Care Medicine, vol. 171, no. 4, pp. 388-416, 2005.

[37] A. Luetz, A. Heymann, F. M. Radtke et al., "Different assessment tools for intensive care unit delirium: which score to use?" Critical Care Medicine, vol. 38, no. 2, pp. 409-418, 2010.

[38] P. S. Hiemstra, P. B. McCray Jr., and R. Bals, "The innate immune function of airway epithelial cells in inflammatory lung disease," European Respiratory Journal, vol. 45, no. 4, pp. 1150-1162, 2015.

[39] P. K. Henke, G. Zamora-Berridi, M. J. Englesbe et al., "A casecohort study of postoperative myocardial infarction: impact of anemia and cardioprotective medications," Surgery (United States), vol. 156, no. 4, article no. 3847, pp. 1018-1029, 2014.

[40] R. Barrera, W. Shi, D. Amar et al., "Smoking and timing of cessation: impact on pulmonary complications after thoracotomy," Chest, vol. 127, no. 6, pp. 1977-1983, 2005.

[41] S. Ghasemi, A. Fotouhi, N. Moslemi, Z. Chinipardaz, J. Kolahi, and M. Paknejad, "Intra- and postoperative complications of lateral maxillary sinus augmentation in smokers vs nonsmokers: a systematic review and meta-analysis," The International Journal of Oral \& Maxillofacial Implants, vol. 32, no. 4, pp. 759767, 2017.

[42] T. Shimazu, S. Kuriyama, K. Ohmori-Matsuda, N. Kikuchi, N. Nakaya, and I. Tsuji, "Increase in body mass index category since age 20 years and all-cause mortality: a prospective cohort study (the Ohsaki Study)," International Journal of Obesity, vol. 33, no. 4, pp. 490-496, 2009.

[43] E. E. Calle, M. J. Thun, J. M. Petrelli, C. Rodriguez, and C. W. Heath Jr., "Body-mass index and mortality in a prospective cohort of U.S. adults," The New England Journal of Medicine, vol. 341, no. 15, pp. 1097-1105, 1999.

[44] E. V. Potapov, M. Loebe, S. Anker et al., "Impact of body mass index on outcome in patients after coronary artery bypass grafting with and without valve surgery," European Heart Journal, vol. 24, no. 21, pp. 1933-1941, 2003.

[45] D. E. Lillenfeld, D. Vlahov, J. H. Tenney, and J. S. McLaughlin, "Obesity and diabetes as risk factors for postoperative wound infections after cardiac surgery," AJIC: American Journal of Infection Control, vol. 16, no. 1, pp. 3-6, 1988.

[46] M. A. Olsen, J. J. Nepple, K. D. Riew et al., "Risk factors for surgical site infection following orthopaedic spinal operations," Journal of Bone and Joint Surgery, vol. 90, no. 1, pp. 62-69, 2008.

[47] O. A. Bamgbade, T. W. Rutter, O. O. Nafiu, and P. Dorje, "Postoperative complications in obese and nonobese patients," World Journal of Surgery, vol. 31, no. 3, pp. 556-561, 2007.

[48] H. Wacha, "Wound infections in abdominal surgery - aetiology, risk factors, antibiotic prophylaxis," Zentralblatt fur Chirurgie, vol. 132, no. 5, pp. 400-410, 2007.

[49] P. J. Offner, E. E. Moore, and W. L. Biffl, "Male gender is a risk factor for major infections after surgery," Archives of Surgery, vol. 134, no. 9, pp. 935-940, 1999.

[50] C. J. Gannon, M. Pasquale, J. K. Tracy, R. J. McCarter, and L. M. Napolitano, "Male gender is associated with increased risk for postinjury pneumonia.," Shock (Augusta, Ga.), vol. 21, no. 5, pp. 410-414, 2004.

[51] I. Nachtigall, S. Tafelski, A. Rothbart et al., "Gender-related outcome difference is related to course of sepsis on mixed ICUs: a prospective, observational clinical study," Critical Care, vol. 15, no. 3, article no. R151, 2011.

[52] S. R. Eachempati, L. Hydo, and P. S. Barie, "Gender-based differences in outcome in patients with sepsis," Archives of Surgery, vol. 134, no. 12, pp. 1342-1347, 1999.

[53] A. Combes, C.-E. Luyt, J.-L. Trouillet, A. Nieszkowska, and J. Chastre, "Gender impact on the outcomes of critically ill patients with nosocomial infections," Critical Care Medicine, vol. 37, no. 9, pp. 2506-2511, 2009.

[54] J. Schröder, V. Kahlke, M. Book, and F. Stüber, "Gender differences in sepsis: Genetically determined?" Shock, vol. 14, no. 3, pp. 307-311, 2000.

[55] J. Schröder, V. Kahlke, K.-H. Staubach, P. Zabel, and F. Stüber, "Gender differences in human sepsis," Archives of Surgery, vol. 133, no. 11, pp. 1200-1205, 1998.

[56] A. G. Sutherland, A. Cook, C. Miller et al., "Older patients are immunocompromised by cytokine depletion and loss of innate immune function after HIP fracture surgery," Geriatric Orthopaedic Surgery \& Rehabilitation, vol. 6, no. 4, pp. 295-302, 2015.

[57] R. A. Garibaldi, D. Cushing, and T. Lerer, "Risk factors for postoperative infection," The American Journal of Medicine, vol. 91, no. 3, pp. S158-S163, 1991. 


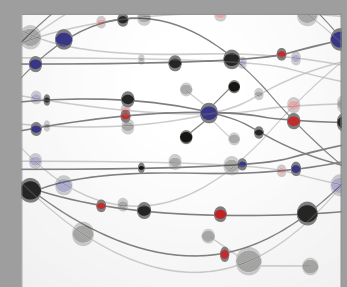

The Scientific World Journal
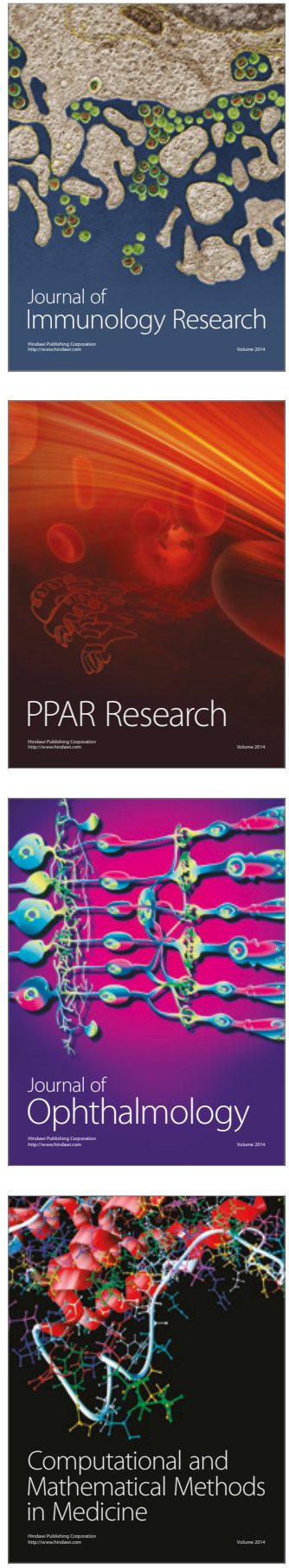

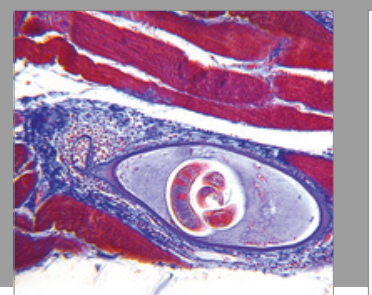

Gastroenterology Research and Practice
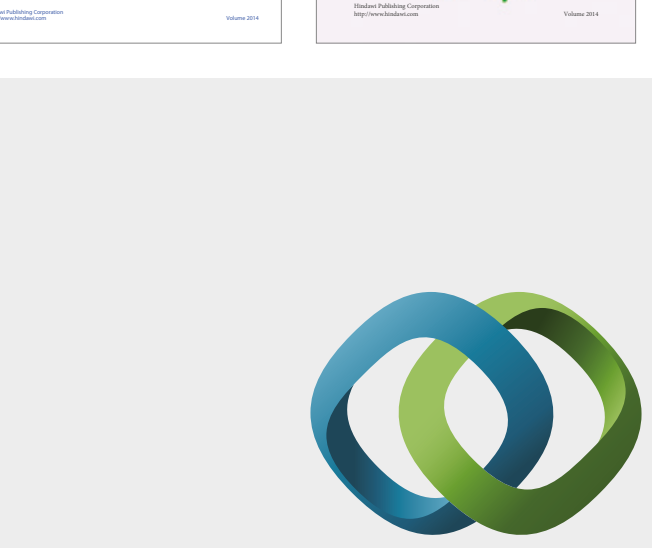

\section{Hindawi}

Submit your manuscripts at

https://www.hindawi.com
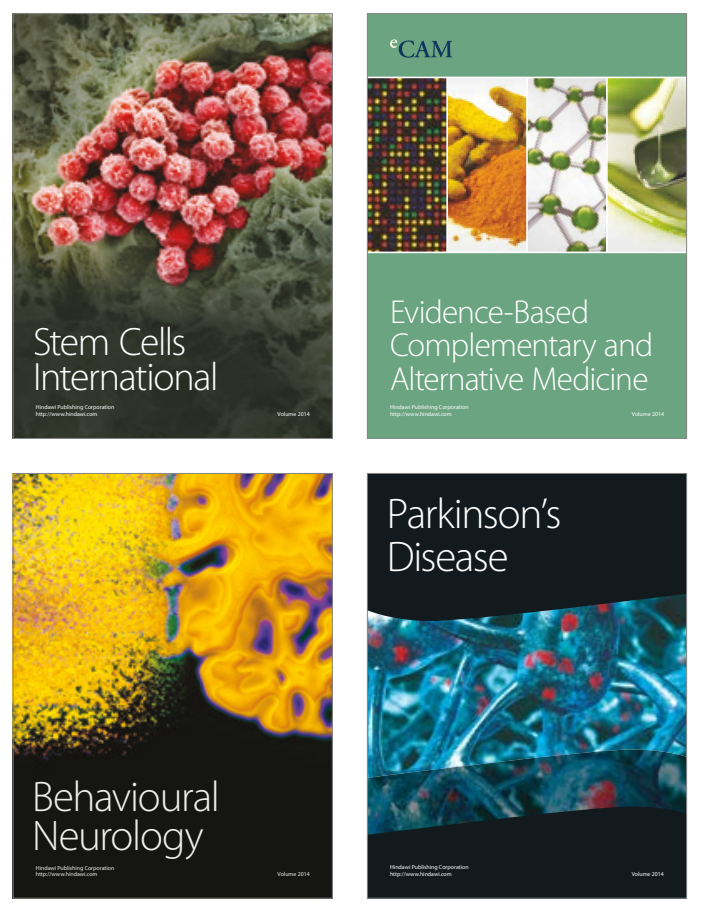
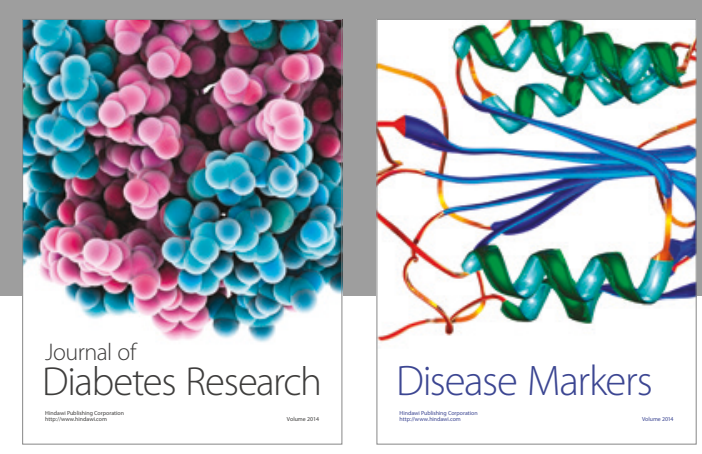

Disease Markers
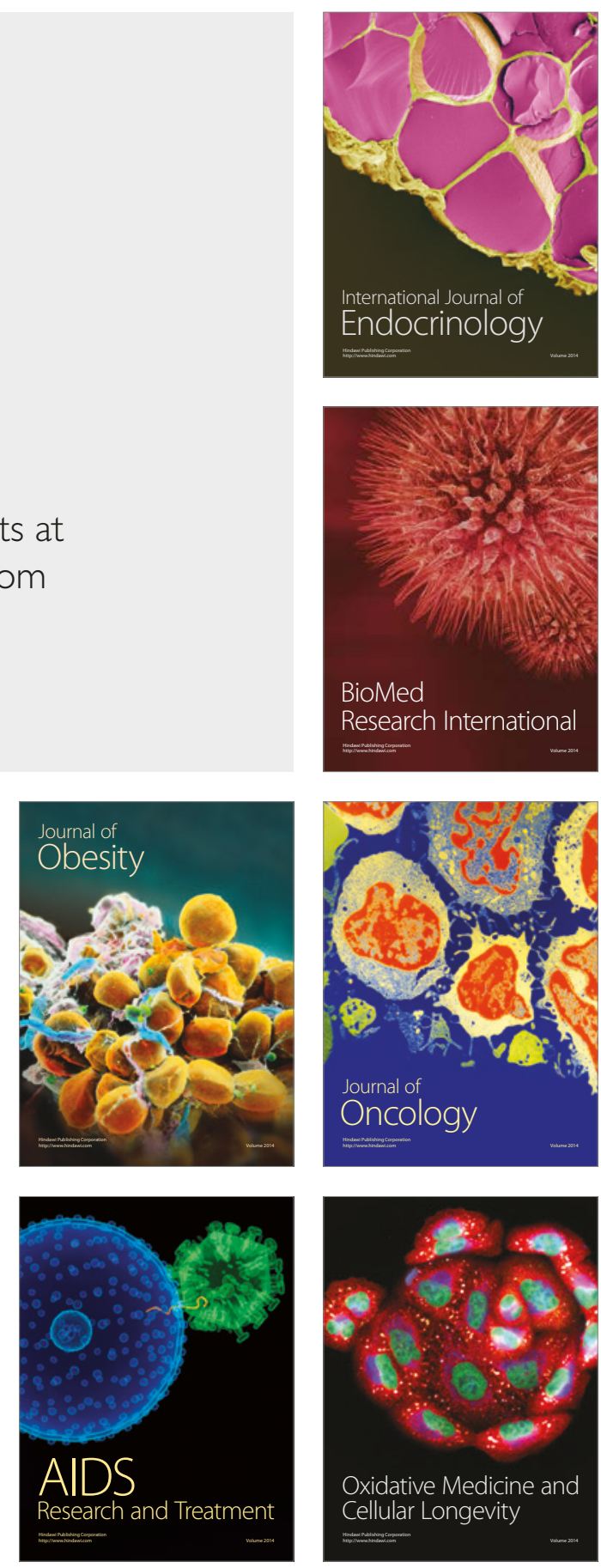